\title{
AIDS presenting as focal segmental membranous glomerulopathy
}

\author{
P S Bass, P J Garrett, D W Ellison, P Terry, S O'Connell, J M Theaker, J R Dathan, \\ D Fine
}

\author{
Department of \\ Histopathology, \\ Southampton \\ University Hospitals, \\ Southampton \\ P S Bass \\ $\mathrm{D}$ W Ellison \\ J M Theaker \\ Department of \\ Nephrology \\ P J Garrett \\ J R Dathan \\ Department of \\ Genitourinary \\ Medicine \\ P Terry \\ Department of \\ Microbiology \\ S O'Connell \\ Department of \\ Medicine \\ D Fine \\ Correspondence to: \\ Dr P S Bass, University \\ Department of Pathology, \\ Level E, South Pathology \\ Block, Southampton \\ University Hospital, \\ Southampton $\mathrm{SO} 94 \mathrm{XY}$ \\ Accepted for publication \\ 29 July 1993
}

\begin{abstract}
The case of a young, heterosexual man who was investigated for proteinuria is reported. A renal biopsy specimen showed a focal and segmental membranous glomerulopathy. He was later found to be HIV positive and died from cerebral infarction associated with HIV vasculitis 16 months after his initial presentation. Unusual forms of immune complex mediated glomerulopathies should alert the pathologist to the possibility of HIV associated disease.
\end{abstract}

$(f$ Clin Pathol 1994;47:179-181)

The association between HIV and renal disease is well documented. ${ }^{1}$ Typically, HIV associated nephropathy (HIVAN) is a rapidly progressive, focal, and segmental sclerosing glomerulopathy with characteristic tubulointerstitial changes, reported to occur predominantly in black, North American, intravenous drug misusers. ${ }^{2}$ Numerous other HIV related glomerular diseases, including IgA nephropathy ${ }^{3}$ and membranous glomerulopathy, ${ }^{4}$ have been reported in HIV positive patients with a variety of risk factors for the infection. Our patient, a heterosexual man with no apparent risk factors for HIV, had an unusual form of membranous glomerulopathy (MGN). Although the pathologist's initial differential diagnosis included infections such as syphilis and hepatitis B, ${ }^{5}$ his HIV infection was only discovered two months after the renal biopsy had been performed.

\section{Case report}

An asymptomatic, 38 year old, white, heterosexual, oil company engineer was found to have proteinuria at a routine employment medical examination and was referred to a renal physician. Clinical examination was normal apart from bilateral inguinal lymphadenopathy. Twenty four hour protein excretion was $3.4 \mathrm{~g}$. Blood pressure and renal function tests were normal. Antibodies to smooth muscle were moderately positive and to neutrophil cytoplasm (ANCA, measured by indirect immunofluorescence) weakly positive. A renal biopsy was performed. Two months later, the renal physician was notified that an HIV antibody screen taken at the time of the employment medical examination was positive. No factors to suggest an increased risk of HIV infection had been identified. $\mathrm{He}$ had previously worked in north and west
Africa for short periods, but had specifically denied sexual activity or possible parenteral exposure during these times.

The tests were repeated and HIV antibodies detected by ELISA, gel particle agglutination, and immunoblot. HIV P24 antigen ELISA was negative. A full blood count and $\mathrm{CD}_{4}$ lymphocyte count were normal. Serological tests for syphilis and hepatitis B markers were negative. A latex agglutination test for Toxoplasma gondii antibody was positive (titre of $>1 / 1024$ ), but the toxoplasma $\operatorname{IgM}$ was negative, consistent with infection acquired some time in the past. Antibodies were also detected by ELISA to herpes simplex, varicella zoster, and cytomegalovirus, indicating earlier infection with these agents.

Eleven months after presentation at the renal clinic, a progressive fall was noted in his $\mathrm{CD}_{4}$ count. Antiviral treatment with zidovudine was started. Dapsone and pyrimethamine were also given as prophylaxis against Pneumocystis carinii infection.

Five months later he required emergency hospital admission. He was febrile, drowsy, and confused. He had a left sixth nerve palsy and right upper motor neurone facial weakness. His right arm and leg were weak with reduced tone, and both plantar responses were extensor.

A brain computed tomogram on the day of admission was normal, but the electroencephalogram (EEG) was highly abnormal, with suppression of the rhythms over the left cerebral hemisphere and additional $\theta$ waves anteriorly. These findings suggested an underlying encephalopathy or early infarction. Microscopic examination, culture, and measurement of the glucose and protein content of the cerebrospinal fluid were unremarkable. Tests performed on serum again showed a toxoplasma latex agglutination titre of $>1 / 1024$ and a negative IgM. Complement fixation tests showed herpes simplex, cytomegalovirus, and varicella zoster antibody titres of $1 / 40,1 / 160$, and $1 / 640$, respectively. Cryptococcal antigen and antibody tests were negative.

Stroke secondary to a primary vascular pathology or possibly herpes zoster infection was diagnosed. Toxoplasma encephalitis was considered unlikely because of the normal computed tomography brain scan appearance. Despite aggressive treatment, including steroids, sulphadiazine, acyclovir and pyrimethamine, he died three days after admission. A necropsy, limited to examination of the brain, was performed. 


\section{Pathological findings}

Light microscopic examination of the renal biopsy specimen showed mild focal and segmental mesangial hypercellularity. Glomerular capillary walls and the tubulo-interstitial and extraglomerular vascular compartments were normal. Immunohistochemical staining (immunoperoxidase and avidin-biotin complex technique) showed diffuse, global, linear and finely granular glomerular capillary wall deposition of $\mathrm{IgG}, \mathrm{IgM}, \mathrm{C}_{3}$ and $\mathrm{Cl}_{\mathrm{q}}$. The mesangium did not stain.

Ultrastructurally, many glomerular capillary loops showed segmental foot process fusion as the only abnormality. An occasional segment, however, showed small, discrete, subepithelial electron dense deposits (fig 1).

At necropsy, the brain weighed $1556 \mathrm{~g}$. Cerebral swelling, most obvious in the left hemisphere, was associated with transtentorial herniation of both parahippocampal

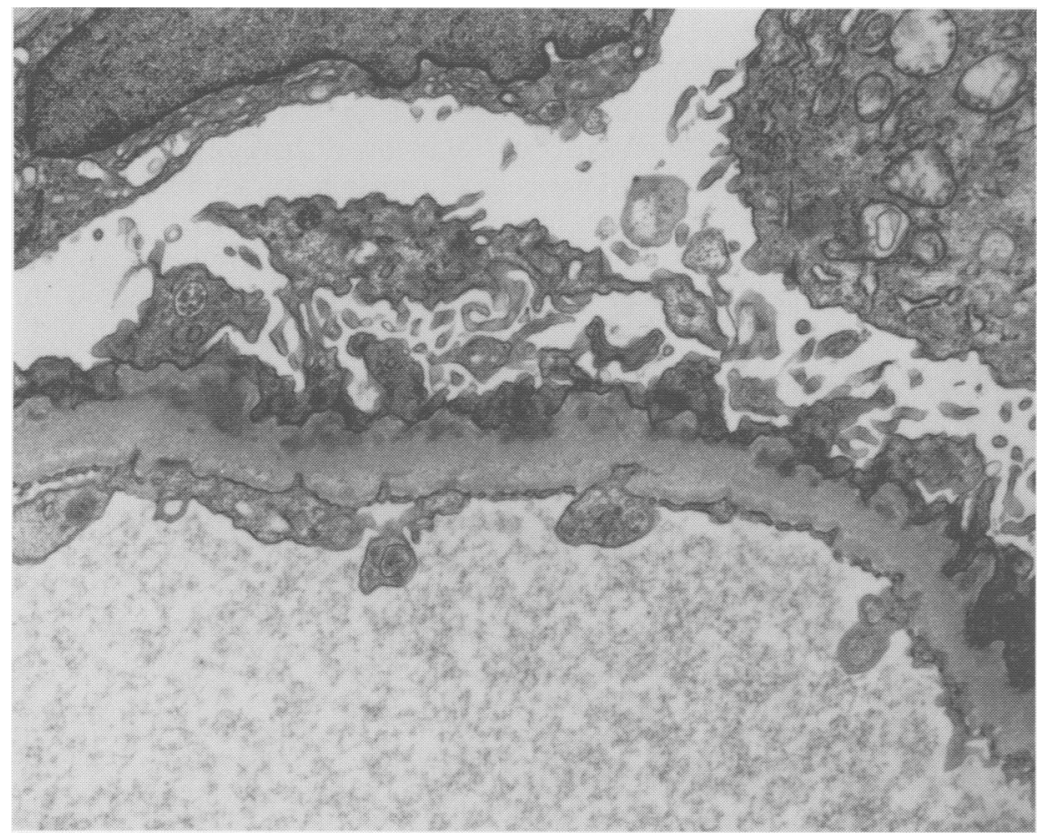

Figure 1 Ultrastructural examination of the renal biopsy specimen showed segmental, subepithelial, electron, dense deposits (uranyl acetate/lead citrate).

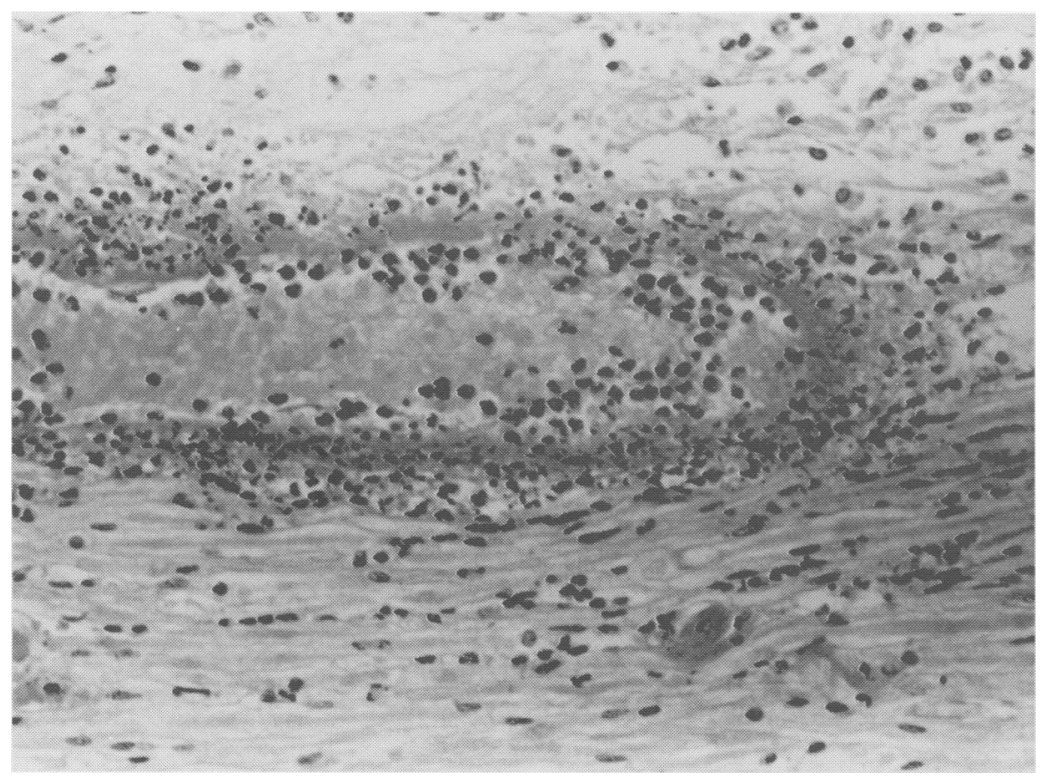

Figure 2 Small vessel vasculitis in the trochlear nerve (haematoxylin and eosin). gyri and herniation of the left cingulate gyrus beneath the falx. The swollen left hemisphere was soft with petechial haemorrhages evident in the superior temporal gyrus. The rostral brainstem was compressed and contained focal haemorrhages secondary to raised intracranial pressure.

Histological examination indicated left cerebral hemisphere infarction in the territories of the middle and posterior cerebral arteries, occurring about 72 hours before death. An adventitial chronic inflammatory infiltrate and intravascular thrombosis coexisted in these vessels. Small areas of infarction in the dorsal pons were associated with an acute vasculitis of small vessels. Polymorph neutrophils invaded the walls of meningeal and parenchymal arterioles and venules, including vessels of the trochlear nerve (fig 2). No specific histological features of HIV or other viral encephalitides or opportunistic infection were seen.

Toxoplasma gondii DNA was detected in brain tissue by gene amplification using the polymerase chain reaction (PCR). ${ }^{6}$ Nested primers were chosen from previously published sequences producing a 97 kilobase probe. A cerebrospinal fluid sample taken two days before death was also probed retrospectively, but $T$ gondii DNA was not detected.

\section{Discussion}

HIVAN is now a well characterised renal disease occurring predominantly in one HIV/AIDS subgroup. However, an ever increasing number of glomerulopathies are described in association with HIV infection. Our case highlights several interesting issues related to HIV infection and systemic disease.

Firstly, as there is a rising incidence of HIV infection in the heterosexual population, ${ }^{7}$ an increase in the number of patients undergoing diagnostic procedures before demonstration of positive HIV serology can be predicted. Interpretation of the histology may be influenced by knowledge of the HIV antibody status. In our patient a renal biopsy specimen showed a focal and segmental MGN. This is occasionally seen in cases of early idiopathic MGN, but, in our experience infections, such as secondary syphilis and hepatitis B, can cause this rather unusual picture. Our patient had no evidence of these diseases. We recommend that HIV infection should be added to the list of possible underlying causes for this histological appearance.

Secondly, the role of Toxoplasma gondii in this man's final illness remains uncertain. The histological and radiological appearances did not suggest active infection in the brain. It is likely that the PCR detected DNA from quiescent encysted organisms in the area of the brain sampled.

Finally, the patient died of intracerebral infarction associated with a vasculitis. The histological picture was consistent with that described for cerebral HIV vasculitis. ${ }^{8}$ Interestingly, our patient was found to have a weakly positive ANCA whilst alive. A recent 
study has shown that some patients with AIDS develop an HIV-ANCA. ${ }^{9}$ It may be that both the presenting and terminal pathological processes in our patient were immunologically mediated, with ANCA possibly playing a part.

We are grateful to Dr EC Guy, Toxoplasma Reference Laboratory, Public Health Laboratory, Singleton Hospital, Swansea, for performance of the $T$ gondii PCR investigations and valuable comments.

1 Glassock RJ, Cohen AH, Danovitch G, Parsa KP. Human immunodeficiency virus (HIV) infection and the kidney. Ai.n Intern Med 1990;112:35-49.

2 Rao TK, Filippone EJ, Nicastri AD, et al. Associated focal and segmental glomerulosclerosis in the acquired immunodeficiency syndrome. $N$ Engl $f$ Med 1984; 310:669-73.

3 Kimmel PL, Phillips TM, Ferreira-Centeno A, Farkas-
Szallasi T, Abraham AA, Garrett CT. Idiotypic IgA nephropathy in patients with human immunodeficiency nephropathy in patients with human immunodef

4 Guerra IL, Abraham AA, Kimmel PL, Sabnis SG Antonovych TT. Nephrotic syndrome associated with chronic persistent hepatitis B in an HIV positive patient. Am F Kidney Dis 1987;10:385-8.

5 Heptinstall RH. Renal manifestations of various infective conditions. In: Heptinstall RH, ed. Pathology of the kidney. 4th Edn. Boston: Little, Brown and Co., 1992: 1935-87.

6 Burg JL, Grover CM, Pouletty P, Boothroyd JC. Direct and sensitive detection of a pathogenic protozoan, Toxoplasma gondii, by polymerase chain reaction. f Clin Microbiol 1989;27:1787-92.

7 Waight PA, Rush AM, Miller E. Surveillance of HIV infection by voluntary testing in England. Communicable Disease Report 1992;2:R85-90

8 Budka H. Neuropathology of human immunodeficiency virus infection. Brain Pathol 1991;1:163-75.

9 Klaasen RJ, Goldschmeding R, Dolman KM, et al. Antineutrophil cytoplasmic antibodies in patients with symptomatic HIV infection. Clin Exp Immunol 1992; 87:24-30.

\title{
Spuriously high free thyroxine with the Amerlite $\mathrm{MAB} \mathrm{FT}{ }_{4}$ assay
}

\author{
L C Lai, J A Day, F Clark, R T Peaston
}

\begin{abstract}
In the Amerlite MAB FT $_{4}$ assay, as stated by the manufacturer, FT $_{4}$ values should be normal in patients with anti-thyroid hormone autoantibodies. The case of a 69 year old woman with a spuriously high FT $_{4}$ using the Amerlite MAB FT 4 assay is reported. Laboratory investigations showed that her spurious FT $_{4}$ result was likely to have been caused by antithyroid hormone autoantibodies.
\end{abstract}

(F Clin Pathol 1994;47:181-182)

It is well documented that anti-thyroid hormone autoantibodies can interfere with the measurement of free thyroxine $\left(\mathrm{FT}_{4}\right)$ and free tri-iodothyronine $\left(\mathrm{FT}_{3}\right){ }^{1}$ In the nonisotopic Amerlite $\mathrm{MAB} \mathrm{FT}$ assay, $\mathrm{FT}_{4}$ in the sample competes with a cross-reactant $T_{3}$, which is chemically bound to the well surface, for binding to a horseradish peroxidase labelled mouse monoclonal anti- $\mathrm{T}_{4}$ antibody. The horseradish peroxidase activity in the bound conjugate is measured by an enhanced luminescence reaction. As stated by the manufacturer, $\mathrm{FT}_{4}$ values should be normal in patients with anti-thyroid hormone autoantibodies using this assay (Amerlite MAB $\mathrm{FT}_{4}$ assay kit insert, Kodak Clinical Diagnostics Ltd; Amersham UK).

\section{Case report}

A 69 year old woman with non-insulin dependent diabetes mellitus and primary biliary cirrhosis had thyroid function tests performed as she had complained of tiredness and was known to have high titres of antithyroid microsomal autoantibodies (1/800) and anti-thyroglobulin autoantibodies $(1 / 1600)$. She also had antimitochondrial IgG (greater than 1/640) and rheumatoid factor (1/40). Her serum thyroid stimulating hormone (Amerlite immunometric assay) was $3.0 \mathrm{mU} / 1$ (reference range: $0.15-3.2 \mathrm{mU} / \mathrm{l}$ ) and her serum total $\mathrm{T}_{3}$ (Amerlex-M $\mathrm{T}_{3}$ radioimmunoassay) was $1.6 \mathrm{nmol} / 1(0.8-2.5$ nmol/1), but her serum $\mathrm{FT}_{4}$ (Amerlite MAB $\mathrm{FT}_{4}$ assay) was unexpectedly and inappropriately high: $92 \mathrm{pmol} / 1 \quad(10-27 \mathrm{pmol} / \mathrm{l})$. This spuriously high $\mathrm{FT}_{4}$ was found on assaying subsequent serum samples from the patient over a period of one year. Her serum albumin was $35 \mathrm{~g} / \mathrm{l}$, total protein was $68 \mathrm{~g} / 1$, and serum protein electrophoresis was normal. The patient was receiving the following medication during the period concerned: tolbutamide, metformin, isosorbide mononitrate, glyceryl trinitrate, diltiazem, cimetidine, digoxin, spironolactone, calciferol, hydroxyapatite and bisacodyl.

\section{Methods and results}

$\mathrm{FT}_{4}$ was measured in the patient's serum using the Boehringer Mannheim assay, which is a competitive immunoassay, and yielded a normal $\mathrm{FT}_{4}$ value of $15 \mathrm{pmol} / 1$ (reference range: $10-26 \mathrm{pmol} / \mathrm{l})$, confirming that the $\mathrm{FT}_{4}$ value obtained with the Amerlite MAB $\mathrm{FT}_{4}$ assay was indeed spuriously high.

Mouse IgG up to $2 \cdot 5 \mathrm{~g} / 1$ (final concentra-
Correspondence to:

Accepted for publication 18 August 1993 